\title{
Sentimentos Empáticos em Crianças, Adolescentes e Adultos ${ }^{1}$
}

\author{
Leonardo Rodrigues Sampaio ${ }^{2}$ \\ Maria Aline Rodrigues Moura \\ Pâmela Rocha Bagano Guimarães \\ Laila Barbosa de Santana \\ Universidade Federal do Vale do São Francisco \\ Cleonice Pereira dos Santos Camino \\ Universidade Federal da Paraíba
}

\begin{abstract}
RESUMO - O objetivo deste trabalho foi avaliar se os tipos de sentimentos empáticos variam em função da faixa etária. Para isso, crianças, adolescentes e adultos do sexo masculino e do sexo feminino foram comparados em suas respostas empáticas a notícias de TV, a partir de entrevistas semi-estruturadas. Os resultados indicaram que os participantes diferenciaram-se conforme a faixa etária, no que se refere aos tipos e intensidade dos sentimentos empáticos. Mais especificamente, observou-se uma frequência mais elevada de respostas relacionadas a experiência de sentimentos empáticos mais complexos como orgulho, injustiça e compaixão entre adultos e adolescentes do que entre as crianças, reforçando o pressuposto de que o desenvolvimento sócio-cognitivo tem papel fundamental para a experiência da empatia.
\end{abstract}

Palavras-chave: empatia, desenvolvimento, tomada de perspectiva

\section{Empathic Feelings in Children, Adolescents and Adults}

\begin{abstract}
The main aim of the present study was to evaluate whether different kinds of empathic feelings varied according to age range. Children's, adolescents' and adults', empathic answers to TV news were compared using a semi-structured interview procedure. Results suggest that age had a significant influence on frequency and intensity of empathic feelings. More specifically, it was observed a higher frequency of more complex empathic feelings such as pride, injustice and compassion among adults and adolescents than children, reinforcing the assumption that socio-cognitive development plays a fundamental role in empathic experiences.
\end{abstract}

Keywords: empathy, development, role-taking

A empatia refere-se a um tipo de resposta com componentes cognitivos e afetivos que permite aos seres humanos acessar os estados internos (cognições e afetos) de seus pares, ao mesmo tempo em que experimentam respostas afetivas congruentes com as informações obtidas a respeito do outro. Essa capacidade de compartilhar as emoções e pensamentos das outras pessoas produz modificações no comportamento de um observador, tal como se ele mesmo estivesse envolvido na situação (Eisenberg, 2000; Hoffman, 2000). Apesar de esta concepção multidimensional do construto da empatia ser amplamente aceita nos dias de hoje por pesquisadores da psicologia (Davis, 1983; Sampaio, Monte, Camino, \& Roazzi, 2008), a história desse conceito está relacionada às teorizações feitas no campo da filosofia e de outras áreas do conhecimento, antes mesmo do advento da ciência psicológica.

A preocupação com os processos por meio dos quais os seres humanos se colocam uns no lugar dos outros e usam essa habilidade para manutenção da vida em sociedade foi ob-

1 Apoio: Fundação de Amparo à Ciência e Tecnologia do Estado de Pernambuco - FACEPE.

2 Endereço para correspondência: Laboratório de Desenvolvimento-Aprendizagem e Processos Psicossociais (LDAPP), Colegiado de Psicologia, Universidade Federal do Vale do São Francisco - UNIVASF, Rua José de Sá Maniçoba, s/n Centro, Petrolina-PE, CEP 56304-205. E-mail: leorsampaio@yahoo.com.br jeto de preocupações de filósofos como Adam Smith, Leibniz e Rosseau (Alves, 2012). Autores como Hume (2000/1739) propunham que as mentes humanas funcionam de maneira muito semelhante e que um afeto que ocorre em uma pessoa é passível de ocorrer nas demais, sendo esse processo denominado de simpatia. Tal como as cordas de um instrumento afinado em um mesmo tom, a simpatia faria com que, a partir da observação das manifestações afetivas alheias, os sentimentos passassem prontamente de uma pessoa à outra, provocando uma espécie de contágio emocional.

No campo da ciência psicológica autores como Lipps, Prandt, Vischer e Brentano teorizaram sobre processos de imitação interna, por meio dos quais as pessoas seriam capazes de acessar e compartilhar os estados mentais umas das outras (Wispé, 1987). Todavia, foi Titchener o primeiro a utilizar o termo empatia no contexto da psicologia, a partir da tradução do conceito alemão Einfühlung, que descreve um processo de projeção do self que permite a um observador de uma obra de arte capturar a essência da obra e experimentar sentimentos de admiração e unicidade por esta. Ao longo dos anos a empatia passou a ser objeto de estudo e reflexão em diversas áreas da psicologia, destacando-se os campos da psicologia da personalidade, psicologia clínica e psicologia social.

Conforme uma revisão feita recentemente por Batson (2009), o termo empatia é empregado nos dias atuais com, 
pelo menos, oito tipos diferentes de significados: 1) forma de se conhecer os estados internos do outro; 2) tipo de imitação interna; 3 ) processo de sentir, vicariamente, com o outro; 4) tipo de intuição; 5) processo de projeção do self ou tomada de perspectiva da situação dos outros; 6) capacidade representativa que permite imaginar os estados internos do outro ou imaginar-se no lugar do outro; 7) tipo de sentimento de ansiedade provocado diante do sofrimento alheio; e 8) compaixão provocada pelo sofrimento ou infortúnio de outrem.

Apesar dessa pluralidade teórico-conceitual, o avanço nesse campo de estudos faz-se necessário, pois muitas evidências empíricas indicam que a empatia tem um importante papel para a vida em sociedade, estando relacionada à pró-sociabilidade (Batson et al, 2003; Eisenberg, 2000; Rameson, Morelli, \& Lieberman, 2011), redução da agressividade na infância (Garaigordobil \& Galdeano, 2006; Moreno \& Fernández, 2011), avanços no julgamento moral (Galvão, Camino, Gouveia, \& Formiga , 2010) e maior responsabilidade pessoal e social (Sanmartín, Carbonell, \& Baños, 2011).

Partindo de uma perspectiva na qual a empatia é vista como produto da evolução humana e na qual a afetividade recebe destaque, Hoffman (2000) propõe que durante os encontros sociais, ao observar as reações emocionais de outra pessoa ou ao simplesmente se imaginar na situação de outrem, um indivíduo pode experimentar, vicariamente, sentimentos que não lhes são adequados naquele contexto e que podem ser chamados de sentimentos empáticos. Assim, este autor define a empatia como um tipo de resposta afetiva que é mais adequada à situação do outro do que a do próprio observador.

No modelo de Hoffman (2000), as sensações de incômodo e desconforto que o bebê experimenta no self, quando se depara com pistas informacionais (ex: entonação de voz, postura corporal, expressões faciais) que indicam a presença de sofrimento em outras pessoas, compõem o sentimento empático mais elementar, chamado de angústia empática (empathic distress). Durante o processo de diferenciação do self, parte da angústia empática é transferida para a representação mental do outro, passando a constituir um novo tipo de sentimento empático chamado de angústia simpática (sympathetic distress), o qual está relacionado à motivação pró-social gerada no self e que predispõe o indivíduo a atuar em prol de outrem.

Além dessa diferenciação inicial da angústia empática para a angústia simpática, Hoffman (1991) propõe que outros sentimentos empáticos surgem ao longo da infância, em consequência do desenvolvimento cognitivo geral e, mais especificamente, do role-taking. Compreendendo que o role-taking refere-se a uma capacidade cognitiva de tomar a perspectiva de alguém, assumir seu ponto de vista e fazer inferências sobre seus pensamentos e sentimentos (Selman \& Byrne, 1974), Hoffman (2000) defende que empatia e role-taking estariam diretamente relacionados ao longo do desenvolvimento. Assim, a capacidade de coordenar e diferenciar diferentes perspectivas permitiria aos sujeitos analisar o contexto no qual as pessoas expressam sua afetividade, fazer atribuições causais sobre a situação observada e sentir vicariamente as experiências afetivas das pessoas à sua volta.

Nesse sentido, à medida que o role-taking avança, a angústia empática e a angústia simpática tendem a se diferenciar em outras formas de sentimentos empáticos, tais como a culpa (quando um indivíduo atribui responsabilidade a si mesmo, seja por omissão ou comissão, ao infortúnio que acontece a outrem), a raiva (quando o sujeito sente raiva de alguém que ofendeu, prejudicou ou machucou um terceiro, mesmo que ele não esteja diretamente envolvido com a situação), a injustiça (quando o indivíduo experimenta uma sensação de incômodo, desconforto ou revolta no self por considerar que alguém foi prejudicado ou favorecido indevidamente) e a tristeza (quando a pessoa fica triste ao observar ou imaginar que alguém passa por uma situação de sofrimento, injustiça ou exclusão, tal como se ele próprio estivesse no lugar daquele outro).

Ainda no que se refere às relações entre desenvolvimento cognitivo e empatia, Hoffman (2000) julga que empatizadores mais maduros, ou seja, aqueles mais velhos e, consequentemente, com capacidade mais elaborada para diferenciar e coordenar diferentes perspectivas, usam de recursos cognitivos mais sofisticados para interpretar e dar sentido aos sentimentos empáticos que experimentam no self. Assim, ao sentirem a ressonância afetiva provocada pela empatia, eles avaliam metacognitivamente a situação, têm consciência sobre como ele e outras pessoas se sentiriam diante daquela circunstância e sabem que, em alguns casos, o que a pessoa externaliza pode não corresponder ao que ela verdadeiramente está sentindo.

Por exemplo, se uma criança acredita que uma pessoa esbarrou intencionalmente em um colega, fazendo com que ele se machucasse, ela pode se colocar no lugar da pessoa que se feriu e sentir raiva empática do colega, mesmo que o esbarrão tenha sido, na verdade, um acidente. Por outro lado, um adulto poderá, de maneira semelhante à criança, sentir raiva, mas será capaz de avaliar a mesma situação e também sentir culpa empática, ao se colocar no lugar da pessoa que machucou a outra sem querer. Nesse sentido, pode-se inferir que o modelo de Hoffman (1991) sugere uma evolução de uma forma egocêntrica da empatia para uma cada vez mais orientada para o outro.

Corroborando o pressuposto de que o desenvolvimento cognitivo repercute diretamente na maneira como as crianças dão significado e interpretam as emoções dos outros, o estudo de León-Rodríguez e Sierra-Mejía (2008) demonstrou que entre os 4 e 6 anos de idade, o avanço na idade implica em uma maior capacidade de compreender as consequências das emoções para as outras pessoas, especialmente quando se trata de situações que evocam emoções positivas (alegria), muito mais do que situações com valência negativa (tristeza).

Objetivando testar um modelo teórico a respeito das relações entre role-taking, empatia, expressividade emocional e comportamento pró-social durante a infância, Roberts e Strayer (1996) desenvolveram um estudo do qual participaram 73 crianças com idades variando entre 5 e 13 anos. Nessa pesquisa, os participantes falavam sobre reações esperadas de personagens que apareciam em pequenas vinhetas com conteúdo emocional, assim como avaliavam (tipo e intensidade) suas próprias respostas emocionais às vinhetas. Outras medidas avaliaram a expressividade facial e emocional dos participantes em casa e na escola, assim como seu comportamento pró-social em uma situação de laboratório. Os resultados demonstraram que a capacidade 
de tomada de perspectiva, a empatia e a expressividade emocional avançavam significativamente entre os grupos etários e que houve correlações positivas e significativas entre as medidas de empatia e de role-taking, e entre a empatia e a expressividade emocional. Ademais, a idade demonstrou ser um bom preditor do role-taking, mas não da empatia e nem do comportamento pró-social. De fato, a idade só pareceu influenciar significativamente a empatia quando mediada pela capacidade de tomada de perspectiva.

Nessa mesma direção, o estudo de Howe, Cate, Brown e Hadwin (2008) indica que o aumento da idade ligado ao avanço cognitivo geral produz mudanças na maneira como a empatia se manifesta em pré-escolares. Utilizando pequenas vinhetas animadas nas quais crianças apareciam em diferentes contextos emocionais e figuras com diferentes expressões faciais como instrumento de avaliação, Howe e seus colaboradores avaliaram a capacidade de participantes com idades variando entre 40 e 53 meses de idade de compreender e compartilhar as emoções dos protagonistas das vinhetas. Nos resultados, constatou-se que o aumento na idade dos participantes, mas não o incremento em suas habilidades verbais, esteve associado à capacidade de compreender e compartilhar as emoções de medo, tristeza, alegria e raiva dos protagonistas. Além disso, houve correlações positivas e significativas entre a compreensão e o compartilhar emocional, e a expressividade facial dos próprios participantes, reforçando a tese de que a compreensão das emoções dos outros estaria associada à responsividade emocional durante a infância.

Através de uma medida baseada na avaliação que pais de crianças entre 1 e 5 anos de idade faziam sobre o comportamento dos seus filhos, a pesquisa de Rieffe, Ketelaar e Wiefferink (2010) ofereceu evidências empíricas a respeito da relação direta entre avanços na idade e a maneira como as crianças experienciam sentimentos empáticos. Mais especificamente, constatou-se nesse estudo a existência de correlações positivas entre a medida de atenção aos sentimentos de outras pessoas e idade, mas nenhuma correlação entre idade e contágio emocional, com a idade sendo um bom preditor do reconhecimento das emoções dos outros e da compreensão emocional.

Partindo do pressuposto de Hoffman (1991, 2000) de que a empatia tende a se transformar à medida que a idade avança e dos achados empíricos supramencionados, esperar-se-ia que, diante de uma situação na qual as outras pessoas manifestam suas emoções, crianças tenderiam a compreender essas manifestações e a empatizar a partir de uma perspectiva mais concreta e imediata, analisando apenas as informações disponíveis no contexto de observação. Adolescentes e adultos, por outro lado, em função do avanço em suas habilidades de simbolização e de tomada de perspectiva, tenderiam a usar as pistas situacionais imediatas, mas também seriam capazes de articulá-las com seus conhecimentos e experiências anteriores, pautando seus julgamentos nos padrões e normas próprias de seu grupo social.

Assim, considerando-se a possibilidade de avaliar empiricamente se haveria diferenças na maneira como a empatia é experienciada em diferentes idades, o objetivo principal deste trabalho foi avaliar se os sentimentos empáticos frente a situações reais nas quais o sujeito assume a perspectiva de um observador inocente eram diferentes entre crianças, ado- lescentes e adultos. Ademais, objetivou-se avaliar se o sexo e a idade estariam relacionados à intensidade das respostas empáticas relatadas pelos participantes após sua exposição a situações-estímulo com potencial para eliciar a empatia.

\section{Método}

\section{Participantes}

Duzentas e cinquenta e quatro pessoas do sexo masculino $(n=107)$ e do sexo feminino $(n=147)$, com idades variando entre 10 e 29 anos $(M=17,20 ; D P=5,00)$, estudantes de escolas públicas $(n=69)$, escolas particulares $(n=35)$ e de uma universidade pública $(n=150)$ das cidades de Petrolina $(P E)$ e Juazeiro (BA) tomaram parte neste estudo. Para fins de análise dos dados os participantes foram organizados em três faixas etárias: crianças, entre 10 e 12 anos de idade $(n=77)$, adolescentes, entre 13 e 17 anos de idade $(n=37)$ e adultos, entre 18 e 29 anos de idade $(n=140)$.

\section{Instrumentos e materiais}

O principal instrumento desta pesquisa foi um roteiro de entrevista semi-estruturada que objetivava identificar os tipos de emoções ou sentimentos desencadeados nos participantes por quatro diferentes reportagens televisivas. Esse roteiro continha questões como: "O que você sentiu ao assistir esta reportagem (que sentimentos/ emoções)?"; "Você poderia me falar um pouco mais sobre este sentimento/ emoção?", "O quê você acha que os pais dessa criança sentiram ao assistir esse vídeo? "Você já viveu alguma situação em que sentiu algo semelhante ao que sentiu agora? Poderia falar-me sobre esta situação?". Além das entrevistas, utilizou-se um pequeno questionário para coletar dados sócio-demográficos dos participantes e uma escala gráfica tipo Likert com cinco graus $(1=$ muito fraco; $5=$ muito forte $)$, para avaliar a intensidade dos sentimentos relatados pelos participantes.

As quatro reportagens utilizadas na coleta de dados foram veiculadas em telejornais de uma emissora de televisão brasileira e selecionadas pela equipe de pesquisa, considerando seu potencial para gerar sentimentos empáticos nos expectadores. Nesse caso, a opção pelo uso de reportagens televisivas se deu pelo fato de a televisão ser um meio de comunicação que está presente na realidade de muitas pessoas, inclusive de crianças e adolescentes, o que permitiu coletar informações sobre os sentimentos empáticos, sem deslocar os participantes do seu contexto cultural (Mesquita \& Soares, 2008).

O primeiro vídeo apresentava o caso de uma babá que era flagrada por uma câmera escondida agredindo fisicamente uma criança de um 1 ano e 9 meses com Síndrome de Down. A segunda reportagem falava de uma mãe que, ao inverter sua rotina diária, provocou a morte da própria filha de 6 meses, ao esquecê-la dentro do carro por cerca de cinco horas. O terceiro vídeo demonstrava o quanto o Brasil gastava para manter seus políticos durante um ano, em comparação com outros países mais desenvolvidos. E a quarta reportagem apresentava uma história de superação vivida por um ex- 
Tabela 1. Sentimentos Relatados no Vídeo da Babá, em Função da Faixa Etária

\begin{tabular}{lccc}
\hline & Crianças (1) & Adolescent. (2) & Adultos (3) \\
\hline Sentimentos & Freq. (\%) & Freq. (\%) & Freq. (\%) \\
Raiva* & $16(21,33)$ & $19(52,77)$ & $73(54,07)$ \\
Tristeza** & $45(60)$ & $9(25)$ & $13(9,62)$ \\
Compaixão & $8(10,66)$ & $4(11,11)$ & $9(6,66)$ \\
Injustiça*** & $1(1,33)$ & $4(11,11)$ & $28(20,74)$ \\
Angústia & $5(6,66)$ & - & $7(5,18)$ \\
Culpa & - & - & $1(0,74)$ \\
Desprezo & - & - & $2(1,48)$ \\
Vergonha & - & - & $2(1,48)$ \\
Total & $\mathbf{7 5}(\mathbf{1 0 0})$ & $\mathbf{3 6}(\mathbf{1 0 0})$ & $\mathbf{1 3 5}(\mathbf{1 0 0 )}$ \\
\hline
\end{tabular}

$*\left[\chi^{2}=57,16\right.$; g.1. $\left.=2 ; p<0,001\right]: 1 \neq 3 \neq 2(p<0,001)$ e $1=2(p=0,612)$.

$* *\left[\chi^{2}=34,86\right.$; g.1. $\left.=1 ; p<0,001\right]: 2 \neq 1 \neq 3(p<0,001)$ e $2=3(p=0,394)$.

$* * *\left[\chi^{2}=39,81\right.$; g.1. $\left.=2 ; p<0,001\right]: 1 \neq 3 \neq 2(p<0,001)$ e $1=2(p=0,180)$.

-morador de rua que, após passar fome e muitas necessidades, conseguiu ser aprovado em cinco concursos públicos.

\section{Procedimentos}

Antes de iniciar este estudo, o mesmo foi apreciado e aprovado por um Comitê de Ética em Pesquisas com Seres Humanos (CAAE - 0004.0.441.000-10). A coleta de dados foi feita individualmente, nas escolas (crianças e adolescentes) e no Laboratório de Desenvolvimento-Aprendizagem e Processos Psicossociais - LDAPP (adultos) da UNIVASF, em horários previamente acordados. Os vídeos eram apresentados um por vez, usando-se um computador portátil. Após a apresentação de cada vídeo, seguia-se a entrevista e a avaliação da intensidade dos sentimentos relatados, solicitando que os participantes indicassem na escala qual a intensidade de cada um dos sentimentos (raiva, tristeza, angústia etc.) que eles haviam sentido. A sequência de apresentação dos vídeos foi randomizada para evitar efeitos de ordem.

\section{Análise dos dados}

As respostas dos participantes foram categorizadas por três juízes que trabalharam conjuntamente, usando o método da análise de conteúdo (Bardin, 2009). Essa categorização objetivou identificar os diferentes tipos de sentimentos empáticos, seguindo a perspectiva de Hoffman (2000) de que a empatia corresponde a uma resposta afetiva mais adequada à situação do outro do que à do próprio observador.

O teste do Qui-quadrado foi utilizado para comparar a frequência de evocação das respostas em cada categoria, em função do sexo e faixa etária dos participantes. Análises de variância foram usadas para verificar a relação entre essas variáveis e as intensidades dos sentimentos relatados pelos participantes. Todas as análises estatísticas foram processadas através do software SPSS, versão 16.

\section{Resultados}

Ao serem questionados sobre o quê sentiram ao assistir às reportagens, os participantes emitiram 54 tipos diferentes de respostas relacionadas a emoções e sentimentos (ex: raiva, tristeza, alegria, nojo, angústia, orgulho, inveja, compaixão etc.) e outros (ex: fé, graça, impotência, inconformismo etc.). Dessas, apenas aquelas nas quais os participantes relatavam estar sentindo uma emoção ou sentimento que, para o momento de coleta de dados, seria mais adequado às pessoas exibidas nas reportagens do quê a eles mesmos foram consideradas como sendo sentimentos empáticos.

Assim, constatou-se que no vídeo da babá foram relatados oito tipos diferentes de sentimentos empáticos: raiva (expressa através de agressividade contra a babá), tristeza (pelo sofrimento causado à criança), compaixão (com o sofrimento da criança e de seus pais), injustiça (por a babá ter se aproveitado da condição de fragilidade da criança), angústia (incômodo, perturbação, desconforto sentidos ao ver o sofrimento da criança), culpa (ao assumir a perspectiva dos pais por terem contratado a babá), desprezo (pelas atitudes da babá) e vergonha (por parte dos pais, por terem contratado a babá). O teste do Qui-quadrado foi usado como um teste de aderência para avaliar a distribuição de respostas de cada sentimento, em função da faixa etária dos participantes e os resultados demonstraram que houve diferenças significativas na frequência com que respostas do tipo raiva, tristeza e injustiça foram emitidas pelas crianças, adolescentes e adultos. Mais especificamente, constatou-se que a maior parte das respostas do tipo tristeza foi emitida por crianças, enquanto que as de raiva e injustiça foram mais frequentemente relatadas por adultos e adolescentes. Destaca-se ainda que apenas os adultos relataram ter sentido culpa, desprezo ou vergonha quando assistiram o vídeo da babá agressora (Tabela 1).

O vídeo do ex-morador de rua eliciou seis tipos de sentimentos empáticos: alegria (pelo protagonista ter conseguido melhorar sua condição de vida), tristeza (pelo sofrimento que ele passou quando morava nas ruas), compaixão (pela condição de miséria anterior do personagem e de outras 
Tabela 2. Sentimentos Relatados no Vídeo no Ex-Morador, em Função da Faixa Etária

\begin{tabular}{lccc}
\hline & Crianças (1) & Adolescent. (2) & Adultos (3) \\
\hline Sentimentos & Freq. (\%) & Freq. (\%) & Freq. (\%) \\
Alegria* & $43(57,33)$ & $24(75)$ & $88(64,23)$ \\
Tristeza** & $25(33,33)$ & $5(15,62)$ & $1(0,72)$ \\
Compaixão & $4(5,33)$ & $1(3,12)$ & $4(2,91)$ \\
Orgulho*** & $3(4,00)$ & $2(6,25)$ & $40(29,19)$ \\
Injustiça & - & - & $3(2,18)$ \\
Angústia & - & $\mathbf{3 2}(\mathbf{1 0 0})$ & $\mathbf{1 3 7}(\mathbf{1 0 0 0 )})$ \\
\hline Total & $\mathbf{7 5}(\mathbf{1 0 0})$ & \\
\hline$*\left[\chi^{2}=41,81 ;\right.$ g.1. $\left.=2 ; p<0,001\right]: 2 \neq 1 \neq 3(p<0,001)$ e $3 \neq 2(p<0,001)$. & \\
$* *\left[\chi^{2}=32,00 ;\right.$ g.1. $\left.=2 ; p<0,001\right]: 2 \neq 1 \neq 3(p<0,001)$ e $1=2(p=0,102)$. & \\
$* * *\left[\chi^{2}=62,53 ;\right.$ g.1. $\left.=2 ; p<0,001\right]: 1 \neq 3 \neq 2(p<0,001)$ e $1=2(p=0,655)$. &
\end{tabular}

pessoas pobres), orgulho (pela conquista e superação após todo o esforço empreendido), injustiça (pela distribuição de renda no país, pelas discrepâncias entre pobres e ricos) e angústia (ao pensar nas vezes em que o ex-morador relatou passar fome, sentir frio ou dormir nas ruas).

Observou-se que as respostas das crianças concentraram-se nas categorias de tristeza e alegria; elas afirmaram sentir alegria quando pensavam que o ex-morador estava bem agora, mas que ficavam tristes quando lembravam tudo o que ele havia passado antes. Por outro lado, a maior parte das respostas dos adolescentes $(75 \%)$ referiu-se à categoria alegria, havendo uma diminuição da frequência do uso da categoria tristeza, quando comparados com as crianças. Por fim, a maior parte dos adultos relatou ter sentido alegria $(64,23 \%)$ e quase $30 \%$ destes relatou ter sentido orgulho pelas conquistas do morador de rua. O resultado do Qui-Quadrado demonstrou que a distribuição das respostas de alegria, tristeza e orgulho diferiu, em função da faixa etária dos participantes (Tabela 2).

As respostas dadas no vídeo da mãe que esqueceu seu bebê dentro de um carro foram organizadas em quatro cate- gorias: tristeza (pela morte da criança e/ou pelo sofrimento da mãe), compaixão (pelos pais do bebê e pela própria criança), angústia (incômodo/ desconforto ao pensar no sofrimento do bebê e dos seus pais) e culpa (ao se colocar no lugar da mãe e atribuir-lhe responsabilidade pelo ocorrido). Importante destacar que a raiva não foi considerada um sentimento empático, mas que houve participantes que relataram ter sentido raiva da mãe, pois, em suas opiniões, esquecer o filho dentro de um carro seria algo impensável para uma mãe. Algumas crianças disseram ainda que a mãe havia feito isso de propósito porque não gostava do seu filho.

De maneira geral, constatou-se que as frequências das categorias de respostas para esse vídeo variou em função da faixa etária: a maioria das crianças $(79,2 \%)$ e dos adolescentes $(70 \%)$ relatou ter sentido tristeza diante da história contada. Por outro lado, os adultos dividiram suas respostas entre as categorias tristeza (49\%), compaixão (39\%) e 11\% angústia. O resultado do Qui-quadrado demonstrou que as frequências das respostas tristeza, compaixão e angústia variaram significativamente em função da faixa etária dos participantes (Tabela 3 ).

Tabela 3. Sentimentos Relatados no Vídeo do Carro, em Função da Faixa Etária

\begin{tabular}{|c|c|c|c|}
\hline & Crianças (1) & Adolescent. (2) & Adultos (3) \\
\hline Sentimentos & Freq. (\%) & Freq. (\%) & Freq. (\%) \\
\hline Tristeza* & $53(79,10)$ & $18(72)$ & 49 (49) \\
\hline Compaixão** & $10(14,92)$ & $5(20)$ & $39(39)$ \\
\hline Angústia*** & $3(4,47)$ & $2(8)$ & $11(11)$ \\
\hline Culpa & - & - & $1(1)$ \\
\hline Total & $66(100)$ & $25(100)$ & $100(100)$ \\
\hline
\end{tabular}


Tabela 4: Sentimentos Relatados no Vídeo sobre a Política, em Função da Faixa Etária

\begin{tabular}{lccc}
\hline & Crianças (1) & Adolescent. (2) & Adultos (3) \\
\hline Sentimentos & Freq. (\%) & Freq. (\%) & Freq. (\%) \\
Raiva* & $13(28,88)$ & $8(34,78)$ & $39(34,21)$ \\
Tristeza** & $21(46,66)$ & $4(17,39)$ & $7(6,14)$ \\
Injustiça*** & $6(13,33)$ & $9(39,13)$ & $61(53,50)$ \\
Culpa & $4(8,88)$ & $2(8,69)$ & $1(0,87)$ \\
Angústia & - & - & $1(0,87)$ \\
Vergonha & $1(2,22)$ & - & $5(4,38)$ \\
\hline Total & $\mathbf{7 5 ( 1 0 0 )}$ & $\mathbf{3 6}(\mathbf{1 0 0})$ & $\mathbf{1 3 5}(\mathbf{1 0 0})$ \\
\hline
\end{tabular}

$*\left[\chi^{2}=27,70 ;\right.$ g.1. $\left.=2 ; p<0,001\right]: 2 \neq 1 \neq 3(p<0,001)$ e $3 \neq 2(p<0,001)$.

$* *\left[\chi^{2}=15,43\right.$; g.1. $\left.=2 ; p<0,001\right]: 2 \neq 1 \neq 3(p<0,001)$ e $3=2(p=0,384)$.

$* * *\left[\chi^{2}=75,50 ;\right.$ g.1. $\left.=2 ; p=0,01\right]: 1 \neq 3 \neq 2(p<0,001)$ e $1=2(p=0,439)$.

As respostas no vídeo sobre os gastos com os políticos brasileiros foram classificadas nas seguintes categorias: raiva (a partir da constatação da exorbitância de gastos com os políticos brasileiros), tristeza (por essa situação ser algo legitimado em nosso país), injustiça (ao comparar a realidade brasileira com a de outros países desenvolvidos e ao comparar o compromisso social dos políticos brasileiros com seus benefícios financeiros), culpa (por não fazer nada para mudar essa situação), angústia (diante da constatação dessa realidade) e vergonha (dos políticos e da população brasileira). Os resultados demonstraram que respostas do tipo raiva e injustiça foram mais frequentes entre adolescentes e adultos e respostas do tipo tristeza foram mais comuns entre as crianças. Destaca-se ainda que alegria não foi considerada um sentimento empático nesse vídeo, mas que 10 crianças e três adolescentes relataram ter sentido alegria ao assistir esse vídeo porque eles alegavam que o Brasil estava em vantagem, "na frente" de outros países. Por fim, não houve diferenças significativas na frequência com que participantes do sexo masculino e do sexo feminino relataram os diferentes sentimentos em cada vídeo (Tabela 4).

As análises de variância demonstraram, com relação ao vídeo do carro, que a tristeza foi o único sentimento cuja intensidade variou significativamente [F $(1,152): 6,02, p=$ $\left.0,01, \eta_{\mathrm{p}}{ }^{2}=0,035\right]$ entre os participantes do sexo feminino $(\mathrm{M}=4.12, \mathrm{DP}=0,89)$ e do sexo masculino $(\mathrm{M}=3,74, \mathrm{DP}$ $=1,02$ ). No vídeo da babá, a intensidade da raiva foi a única dentre os sentimentos empáticos relatados que variou significativamente [F (1,155): 4,37, $\left.p=0,03, \eta^{2}=0,027\right]$ entre os participantes do sexo feminino $(\mathrm{M}=4.51, \mathrm{DP}=0,68)$ e participantes do sexo masculino $(\mathrm{M}=4.26, \mathrm{DP}=0,79)$. Ademais, não se evidenciou nenhuma influência significativa da faixa etária sobre a intensidade dos sentimentos relatados nesse vídeo.

Com respeito ao vídeo do ex-morador de rua, o sexo não exerceu influência significativa sobre os sentimentos empáticos, mas a intensidade média da alegria foi significativamente diferente [F $\left.(2,191): 4,09, p=0,01, \eta_{\mathrm{p}}{ }^{2}=0,041\right]$ entre crianças
$(\mathrm{M}=4,27, \mathrm{DP}=0,78)$, adolescentes $(\mathrm{M}=3,77, \mathrm{DP}=0,04)$ e adultos $(\mathrm{M}=4,03, \mathrm{DP}=0,74)$. O post hoc Test de Tukey indicou que a diferença foi significativa apenas quando se comparou as crianças com os adolescentes $(p<0,01)$.

No que concerne ao vídeo dos políticos, a ANOVA indicou que a faixa etária dos participantes exerceu influência significativa sobre os sentimentos de raiva $[\mathrm{F}(2,94): 8,57$, $\left.p<0,001, \eta_{\mathrm{p}}{ }^{2}=0,15\right]$, tristeza [F $(2,47): 3,87, p=0,02, \eta_{\mathrm{p}}{ }^{2}$ $=0,14]$ e injustiça $\left[\mathrm{F}(2,88): 8,56, p<0,001, \eta_{\mathrm{p}}{ }^{2}=0,16\right]$. $\mathrm{O}$ post hoc Test de Tukey indicou que a diferença na intensidade média da raiva neste vídeo foi significativa $(p<0,001)$ entre crianças $(\mathrm{M}=3,06, \mathrm{DP}=0,87)$ e adultos $(\mathrm{M}=3,93, \mathrm{DP}=$ $0,87)$. Adultos $(\mathrm{M}=3,89, \mathrm{DP}=1,07)$ e crianças $(\mathrm{M}=3,14$, $\mathrm{DP}=0,71)$ também diferiram $(p=0,022)$ na maneira como avaliaram a intensidade da tristeza. Já para a injustiça, a diferença foi significativa comparando-se a intensidade média relatada pelas crianças $(\mathrm{M}=3,20, \mathrm{DP}=0,83)$ e a dos adultos $(\mathrm{M}=4,24, \mathrm{DP}=0,77, p=0,031)$ e a dos adultos com a relatada pelos adolescentes $(\mathrm{M}=3,12, \mathrm{DP}=1,64, p=0,003)$.

\section{Discussão}

De maneira geral, os resultados do presente estudo demonstraram que os tipos de sentimentos empáticos relatados após a exposição aos vídeos variaram significativamente em termos de conteúdo e de intensidade, em função da idade dos participantes. Esses dados apontam para o papel que o desenvolvimento cognitivo exerce sobre as respostas empáticas geradas em situações nas quais o sujeito assume a perspectiva de um observador inocente (Hoffman, 2000). Mais especificamente, acredita-se que avanços no role-taking estiveram associados a diferenças no uso de determinados tipos de respostas dos participantes de diferentes idades. Isto porque, essa habilidade cognitiva se desenvolve possibilitando que o sujeito coordene múltiplos elementos, ao observar uma situação complexa (Piaget, 1976) e torne-se capaz de assumir as diferentes perspectivas dos sujeitos envolvidos na situação (Selman, 1976). 
Nesse sentido, considera-se que os resultados encontrados confirmaram as expectativas iniciais do estudo, pois o relato dos adultos indicou que os seus sentimentos estiveram associados a informações não explícitas nas situações-estímulo. Por exemplo, ao tentar explicar o que sentiram após assistirem os vídeos, os adolescentes e adultos falavam sobre questões ligadas à distribuição da riqueza no país (vídeo sobre o ex-morador de rua), injustiça social (vídeo sobre os políticos) e aos direitos constitucionais das crianças (vídeos da babá e da criança esquecida no carro). Considera-se que esse conhecimento acerca da realidade social brasileira os levou a construir teorias sobre a responsabilidade, participação e envolvimento dos protagonistas dos vídeos, o que fez com que determinados sentimentos empáticos fossem ativados.

Ainda sobre essa questão, cita-se o exemplo do sentimento de injustiça no vídeo da babá, pois os relatos dos adultos e adolescentes direcionavam o foco da avaliação para a existência de algum tipo de desequilíbrio na relação de poder entre a babá e a criança. No vídeo da política, por sua vez, as respostas de injustiça dos adolescentes e adultos estiveram relacionadas a uma avaliação de que o salário recebido pelos políticos brasileiros seria desproporcional ao trabalho que eles exercem e injustos quando comparados com a renda da maior parte da população.

Outros resultados sugerem que as crianças assumiram, mais frequentemente, a perspectiva dos protagonistas que também eram crianças, o que provavelmente as fez sentir mais tristeza do que os adultos e adolescentes nos vídeos da babá e da mãe que esqueceu o filho dentro do carro. Além disso, acredita-se que elas tenham tido dificuldades para assumir outros pontos de vista, fazendo com que algumas relatassem ter sentido raiva da mãe que esqueceu seu bebê no carro, ao julgarem que ela havia feito isso intencionalmente.

Os adolescentes e os adultos, por sua vez, puderam assumir a perspectiva dos protagonistas infantis, mas também a dos adultos, o que os fez experimentar tristeza e outros sentimentos que seriam adequados à situação dos pais das crianças (vídeo sobre a babá e sobre a mãe que esqueceu o bebê no carro). Além de indicar a existência de uma relação entre role-taking e empatia, esses dados sugerem a existência de um viés da familiaridade-similaridade nos sentimentos empáticos dos participantes, tal como sugere Hoffman (1991), pois as crianças empatizaram mais com crianças, enquanto que os adultos e adolescentes tenderam a empatizar mais com os adultos.

Outro dado que aponta para uma capacidade mais ampla dos adolescentes e adultos para assumir o ponto de vista dos protagonistas dos vídeos refere-se às diferenças na intensidade dos sentimentos de raiva, injustiça e tristeza no vídeo sobre os políticos brasileiros. Era esperado que esse vídeo mobilizasse afetivamente mais aqueles participantes que pudessem fazer uma análise crítica da situação, contextualizando-a em uma rede de informações mais ampla do que aquela fornecida apenas pelas pistas situacionais disponíveis no vídeo.

Nessa direção, os resultados da análise de variância corroboraram as expectativas iniciais a respeito das relações entre o desenvolvimento psicossocial e empático, pois os adolescentes e adultos foram justamente aqueles que relataram ter sentido raiva, injustiça e angústia mais intensas, diante das disparidades apresentadas no vídeo. Ainda sobre esse vídeo, a presença de respostas do tipo alegria entre crianças e adolescentes sugere que as pistas situacionais disponíveis levaram alguns participantes a julgar que um gasto mais elevado implicaria em algum tipo de vantagem para o Brasil e que isso seria um motivo para eles se alegrarem.

Mesmo considerando que os resultados apontam para uma ampliação na capacidade de tomada de perspectiva relacionada à idade, é importante relembrar que não houve relato de nenhum sentimento empático direcionado à babá no vídeo em que esta agredia uma criança. Ou seja, os participantes parecem ter assumido a perspectiva apenas de uma das partes envolvidas na situação, no caso a vítima, não sendo, portanto, o transgressor passível de compaixão por parte dos respondentes. Esse dado aponta para a existência de outros vieses na empatia que precisam ser mais bem investigados em estudos posteriores, especialmente no que tange às relações entre as motivações geradas pelos sentimentos empáticos e a moralidade.

No que se refere às diferenças relacionadas ao sexo, os resultados aqui encontrados vão na direção do que autores como Lennon e Eisenberg (1987) defendem quando afirmam que apesar de haver evidências empíricas que sugerem a influência do sexo sobre a empatia, ainda não há consenso a respeito dessa questão. Esses autores apontam para a existência de vieses socioculturais que levariam homens e mulheres a se diferenciar em estudos com medidas auto avaliativas, mas que essas diferenças tenderiam a desaparecer em pesquisas que usam medidas mais objetivas para avaliar a empatia.

De qualquer maneira, é interessante pensar no porquê das mulheres terem relatado sentir tristeza e raiva mais intensos que os homens nos vídeos do carro e da babá, respectivamente. Destaca-se que esses dois vídeos eram justamente aqueles que envolviam mais aspectos ligados ao cuidado, especialmente na relação entre pais e filhos e que a preocupação com temáticas como essas seria justamente uma característica socialmente reforçada mais nas mulheres do que nos homens. Assim, concorda-se com alguns autores (Cecconello \& Koller, 2000; Escrivá, Garcia, \& Navarro, 2002; Escrivá, Navarro, \& Garcia, 2004; Garaigordobil \& Galdeano, 2006; Sampaio et al., 2008) que afirmam que as diferenças nos papéis sociais atribuídos a homens e mulheres seriam uma importante variável que ajudaria a explicar as diferenças de sexo relacionadas à empatia.

Outro aspecto que merece ser discutido refere-se a uma possível influência do desenvolvimento linguístico sobre os resultados aqui encontrados. De uma maneira geral observou-se que os adultos e adolescentes usaram uma diversidade muito maior de termos para descrever e explicar o que eles haviam sentido quando assistiam aos vídeos, em comparação ao vocabulário usado pelas crianças. Essas usaram mais frequentemente termos que designam emoções primárias (Damasio, 2007/1996) como tristeza, alegria e raiva, e poucas vezes termos como compaixão, angústia e injustiça. Por outro lado, os adolescentes e adultos lançaram mão de um vocabulário mais amplo que as crianças, empregando termos como ojeriza, indignação, nojo e insatisfação, ao mesmo tempo em que também usavam palavras relacionadas a emoções primárias.

Apesar de os respondentes mais velhos terem demonstrado maior desenvoltura que os mais jovens para descrever suas 
experiências emocionais, muitos relataram sentir uma grande dificuldade para relatar/nomear os próprios sentimentos, o que aponta para uma possível limitação do presente estudo, já que a principal variável dependente analisada baseava-se no relato verbal dos participantes. Ademais, julga-se que é possível que aquilo que algumas crianças chamaram de tristeza represente, na verdade, algum tipo de angústia empática (Hoffman, 2000), pois elas diziam que aquela tristeza era "ruim", "dava uma dor no peito", fazia "elas se sentirem mal". Esse dado aponta para uma cautela na interpretação de resultados provenientes de autorrelatos em crianças, especialmente quando se consideram os resultados do estudo de Anastassiou-Hadjicharalambous e Warden (2007), no qual os investigadores observaram uma baixa correlação entre medidas da empatia do tipo verbal (autoavaliativas) e de expressões faciais em crianças, além da ausência de correlações significativas entre medidas verbais e fisiológicas da empatia.

Nesse sentido, estudos futuros poderiam buscar associar a abordagem utilizada aqui com outra na qual fossem utilizados diferentes tipos de medidas da empatia, como a avaliação pelos pares e/ou cuidadores e a observação do comportamento em situações de interação social. Outra sugestão para estudos futuros seria a de adotar uma abordagem na qual a habilidade de tomada de perspectiva pudesse ser avaliada por meio de medidas específicas para tal finalidade. Essa estratégia metodológica poderia levar à confirmação dos resultados aqui encontrados, além de possibilitar uma investigação mais precisa a respeito da relação entre empatia e os estágios de desenvolvimento do role-taking e da descentração.

De maneira geral, considera-se que os resultados do presente estudo confirmam a hipótese de Hoffman (2000) de que a empatia atua como uma "cola que torna a vida social possível”, funcionando como uma espécie de sistema informacional que permite aos seres humanos acessarem as experiências internas de seus semelhantes, ao mesmo tempo em que modificam seu próprio comportamento.

No caso do presente estudo, os resultados indicam que saber (cognitivamente) e sentir (vicariamente) o que os protagonistas dos vídeos estavam sentindo motivou os participantes a se posicionarem criticamente frente às situações-estímulo. Em alguns casos, essas experiências empáticas motivaram alguns participantes a querer fazer algo para acabar com o sofrimento dos indivíduos pelos quais eles sentiram empatia ou a lutar contra algo que eles consideravam ser injusto, o que reforça a necessidade de desenvolvimento de outros estudos nos quais as relações entre o desenvolvimento da empatia, a moralidade e a vida em sociedade possam ser investigadas de maneira sistemática e profunda.

\section{Referências}

Alves, S. A. (2012). A relação entre capacidades empáticas, depressão e ansiedade em jovens. Dissertação de Mestrado não publicada, Universidade Federal da Paraíba, João Pessoa.

Anastassiou-Hadjicharalambous, X., \& Warden, D. (2007). Convergence between physiological, facial and verbal selfreport measures of affective empathy in children. Infant and Child Development, 16, 237-254.
Bardin, L. (2009). Análise de conteúdo. Lisboa: Edições 70.

Batson, C. D. (2009). These Things Called Empathy: Eight related but distinct phenomena. In J. Decety \& W. Ickes (Eds.), The Social Neuroscience of Empathy (pp. 3-16). Cambridge: MIT Press.

Batson, C. D, Lishner, D. A., Carpenter, A., Dulin, L., HarjusolaWebb, S., Stocks, E. L., Sampat, B. (2003). “...As you would have them do unto you": Imagining yourself in the other's place stimulate moral action? Personality and Social Psychology Bulletin, 29(9), 1190-1201.

Cecconello, A. M., \& Koller, S. H. (2000). Competência social e empatia: um estudo sobre resiliência com crianças em situação de pobreza. Estudos de Psicologia (Natal), 5(1), 71-93.

Damasio, A. R. (2007). O erro de Descartes: emoção, razão e o cérebro humano. São Paulo: Companhia das Letras. (Trabalho original publicado em 1996)

Davis, M. H. (1983). Measuring individual differences in empathy: evidence for a multidimensional approach. Journal of Personality and Social Psychology, 44(1), 113-136.

Eisenberg, N. (2000). Emotion, regulation and moral development. Annual Review of Psychology, 51, 665-697.

Escrivá, V. M., Garcia, P. S., \& Navarro, M. D. F. (2002). Procesos cognitivos y emocionales predictores de la conducta prosocial y agresiva: La empatía como factor modulador. Psicothema, 14(2), 227-232.

Escrivá, V. M., Navarro, M. D. F., \& Garcia, P. S. (2004). La medida de la empatía: análisis del Interpersonal Reactivity Index. Psicothema, 16(2), 255-60.

Galvão, L. K. S., Camino, C. P. S., Gouveia, V. V., \& Formiga, N. (2010). Proposta de uma medida de empatia focada em grupos: validade fatorial e consistência interna. Psico (PUCRS. Impresso), 41(3), 339-405.

Garaigordobil, M., \& Galdeano, P. G. (2006). Empatía en niños de 10 a 12 años. Psicothema, 18(2), 180-186.

Hoffman, M. L. (1991). Empathy, social cognition and moral action. In W. M. Kurtines, \& J. L. Gewirtz (Eds.), Handbook of moral behavior and development (pp. 65-87). New Jersey: LEA.

Hoffman, M. L. (2000). Empathy and moral development: implications for caring and justice. New York: Cambridge University Press.

Howe, A., Cate, I. M. P., Brown, A., \& Hadwin, J. (2008). Empathy in preschool children: the development of the Southampton Test of Empathy for Preschoolers (STEP). Psychological Assessment, 20(3), 305-309.

Hume, D. (2000). Tratado da Natureza Humana: uma tentativa de introduzir o método experimental de raciocínio nos assuntos morais (D. Danowski, Trad.) São Paulo: Editora UNESP (Trabalho original publicado em 1739)

Lennon, R. \& Eisenberg, N. (1987). Gender and age differences in empathy and sympathy. In N. Eisenberg, \& J. Strayer (Eds.), Empathy and its development (pp. 195-217). Cambridge University Press: New York.

León-Rodríguez, D. \& Sierra-Mejía, H. (2008). Desarrollo de la comprensión de las consecuencias de las emociones. Revista Latinoamericana de Psicología, 40(1), 35-45.

Mesquita, N. A. S., \& Soares, M. H. F. B. (2008). Visões de ciência em desenhos animados: uma alternativa para o debate sobre a construção do conhecimento científico em sala de aula. Ciência e Educação [online], 14 (3), 417-429. 
Moreno, J. E. \& Fernández, C. (2011). Empatía y flexibilidad yoica, su relación con la agresividad y la prosocialidad. Límite: Revista de Filosofía y Psicología, 6(23), 41-55.

Piaget, J. (1976). Equilibração das estruturas cognitivas - problema central do desenvolvimento. Rio de Janeiro: Zahar Editores.

Rameson, L. T., Morelli, S. A., \& Lieberman, M.D. (2011). The neural correlates of empathy: experience, automaticity, and prosocial behavior. Journal of Cognitive Neuroscience, 24(1), 235-245.

Rieffe, C., Ketelaar, L., \& Wiefferink, C. H. (2010). Assessing empathy in young children: construction and validation of an empathy questionnaire (EmQue). Personality and Individual Differences, 49(5), 362-367.

Roberts, W., \& Strayer, J. (1996). Empathy, emotional expressiveness and prosocial behavior. Child Development, 67, 449-470.

Sanmartín, M. G, Carbonell, A. E., \& Baños, C. P. (2011). Relaciones entre empatía, conducta prosocial, agresividad, autoeficácia y responsabilidad personal y social de los escolares. Psicothema, 23(1), 13-19.

Sampaio, L. R., Monte, F. C., Camino, C., \& Roazzi, A. (2008). Justiça distributiva e empatia em adolescentes do nordeste brasileiro. Psicologia: Reflexão e Crítica, 21(2), 275-282.
Selman, R. L. (1976). Social-cognitive understanding. A guide to educational and clinical practice. In T. Lickona (Ed.), Moral development and behavior: theory, research and social issues (pp.299-316). New York: Holt, Rinehart \& Winston.

Selman, R. L., \& Byrne, D. F. (1974). A structural analysis of levels of role-taking in middle childhood. Child Development, 45, 805-803.

Wispé, L. (1987). History of the concept of empathy. In N. Eisenberg, \& J. Strayer (Eds.), Empathy and its development (pp.17-37). New York: Cambridge University Press.

Recebido em 08.12.2010

Primeira decisão editorial em 21.03.2012

Versão final em 15.04.2012

Aceito em 31.07.2013 